\title{
ArcheoSciences
}

Revue d'archéométrie

\section{Targeting Ion Beam Analysis techniques for gold artefacts}

Techniques de faisceaux d'ions ciblés pour l'analyse d'objets en or

\section{Guy Demortier}

\section{(2) OpenEdition \\ 1 Journals}

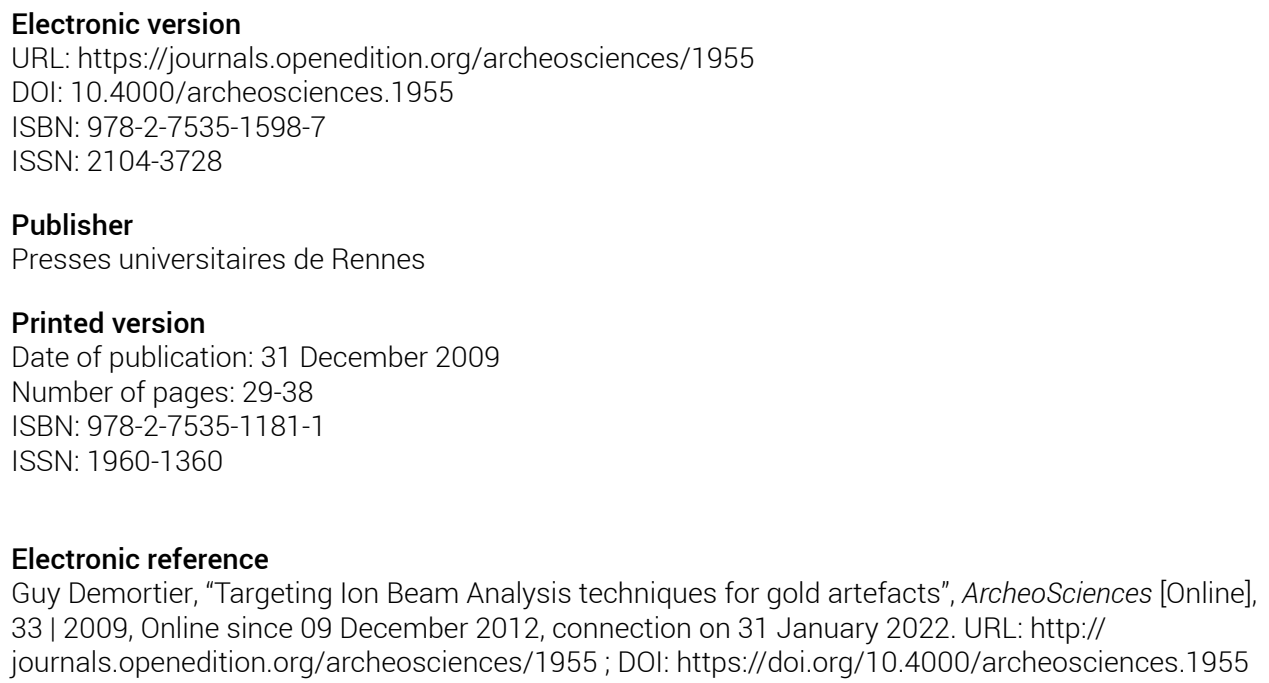

Article L.111-1 du Code de la propriété intellectuelle. 


\title{
Targeting Ion Beam Analysis techniques for gold artefacts
}

\author{
Techniques de faisceaux d'ions ciblés pour l'analyse d'objets en or
}

\author{
Guy Demortier*
}

\begin{abstract}
The present study discusses the best experimental conditions for the quantitative analysis of gold jewellery artefacts by ion beam techniques (PIXE, RBS, PIGE and NRA). Special attention is given to the detection of enhancement or depletion below the surface, down to 10 microns, without any sampling or destruction. PIXE is certainly the most interesting technique for this purpose and the optimal geometrical arrangement of the experiment is described: orientation of the incident beam relative to sample surface, selection of the characteristic signals, use of reference material, choice of the detector and incident particle energy and type, computation of absorption and secondary fluorescence effects.

Résumé : Nous discutons des conditions idéales d'utilisation des faisceaux de particules pour l'étude d'objets en or (PIXE, RBS, PIGE, et NRA). On attache une attention particulière au choix des paramètres expérimentaux pour détecter la présence éventuelle d'effets de surface sur une profondeur de l'ordre de 10 microns, sans prélèvement ni destruction. Le PIXE s'avère la technique idéale pour autant qu'on prenne en compte une série de paramètres comme l'orientation du faisceau incident relativement à la surface, choix des signaux pour la caratérisation, choix des échantillons de référence, choix du détecteur, choix de l'énergie et du type des particules incidentes, calcul des effets d'absorption et de fluorescence secondaire.
\end{abstract}

Keywords: PIXE, PIGE, RBS, NRA, surface enrichment, fluorescence effects, solders

Mots-clés : PIXE, PIGE, RBS, NRA, enrichissement superficiel, effets de fluorescence, soudures.

\section{INTRODUCTION}

Gold artefacts are often considered as un-corroded items which can be analysed for their bulk composition by surface techniques probing thicknesses of one micron or more. All of these methods involve ion beam techniques using accelerators delivering particles in the $\mathrm{MeV}$ range. We have demonstrated that this statement is not absolute (Ruvalcaba and Demortier, 1996; Demortier and Ruvalcaba, 2005), and that surface enhancement of gold (and consequently copper depletion) is often verified in pre-Columbian jewellery items. The presence of this enhancement can be rapidly identified by PIXE with incident protons of at least two different energies.

In the present study, we discuss the best experimental conditions required to quantitatively profile the elemental depth distribution of Au vs. $\mathrm{Cu}$ and $\mathrm{Ag}$ by PIXE and RBS, but also to analyse low concentrations of elements like Fe, $\mathrm{Zn}, \mathrm{Cd}$ by PIXE, and low Z elements like Al, Si and S, which are often present as dust or remains of the alloying procedure, but at low concentration, in the surface grain boundary of the basic $\mathrm{Au}-\mathrm{Ag}-\mathrm{Cu}$ alloy.

* LARN (University of Namur - Belgium) and CEDAD (University of Salento - Italy), 24, rue Sergent Delisse B-5004 Bouge. (guy.demortier@ tvcablenet.be) 


\section{AVAilable ION BeAm TECHNIQUeS With LOW ENERGY ACCELERATORS FOR THE ANALYSIS OF GOLD JEWELLERY ARTEFACTS}

When a material is irradiated with charged particles like protons, deuterons, $\alpha$-particles or other heavier ions, with energy ranging from a few hundred $\mathrm{keV}$ to a few $\mathrm{MeV}$, the emission of photons, charged particles and neutrons makes available various spectroscopic methods of elemental analysis. The great majority of the interactions of the incident charged particles with the atoms of the irradiated material take place with atomic electrons: the incident particle progressively loses its energy and stops after crossing a distance $\mathrm{R}$, known as the range. By interacting mainly with atomic electrons and since interaction with an atomic nucleus occurs only rarely, this incident particle does not experience an appreciable deviation. The range $\mathrm{R}$ is then nearly the total distance that the particle travels following a straight line in the material. $\mathrm{R}$ increases with the incident projectile energy $\left(R \sim E^{1.8}\right)$, and decreases with the atomic number $Z$ and its mass $\mathrm{M}$.

This property of a linear trajectory of protons in the materials allows us to use them to irradiate the material under analysis outside the vacuum of the accelerator. The incident beam crosses a thin foil of material (mostly aluminium, kapton or silicon nitride), as shown in Figure 1, where we have compared the trajectories of incident protons and electrons on a metallic target. The simple linear trajectory of the incident protons contrasts with the complicated one of electrons. One immediately sees the advantage of using an external proton beam for the easy positioning of the artefact outside the vacuum chamber of the accelerator. Since the pioneering work of the LARN team in 1972 (Deconninck, 1972), constant improvements of the external beam technology have been made in many laboratories involved in archaeometry. The interaction of the incident protons with the atomic electrons of the target (i.e., the sample under investigation) induces ionisation. When ionisation takes place in an inner electronic shell, a subsequent electronic rearrangement to return to an atomic equilibrium leads to the emission of characteristic X-rays: the analytical technique based on this atomic process is called PIXE (Particle Induced X-ray Emission). PIXE is a very sensitive method for the bulk and trace analysis of elements with an atomic number $\mathrm{Z}$ greater than 20. PIXE may also be used for the study of elements from $\mathrm{Na}$ to $\mathrm{K}$, but the absorption of the low energy characteristic X-rays (1-3 keV) of these light elements into thick samples generally restricts the potentiality of the method for quantitative determination.

When an incident particle passes very close to the atomic nucleus, it may be elastically scattered. At very low impact parameters, an incident particle of mass $\mathrm{m}$, lower than the mass $\mathrm{M}$ of the collided nucleus, can be scattered at an angle close to $180^{\circ}$. The spectroscopy of these backscattered particles (RBS) is often recommended for depth profiling of elements with thicknesses up to $30 \%$ of their own range. The energy of the backscattered particle is related to the mass of the collided nucleus

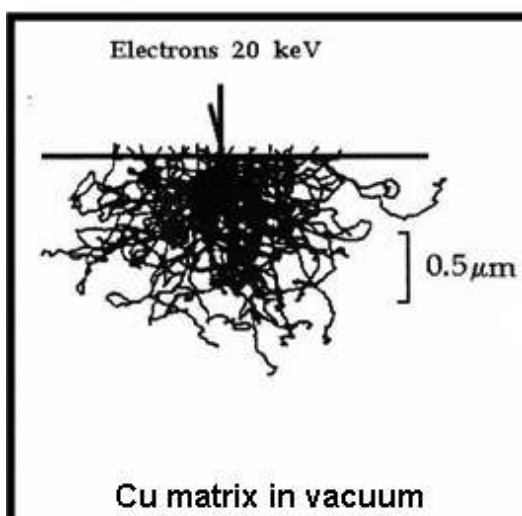

(a)

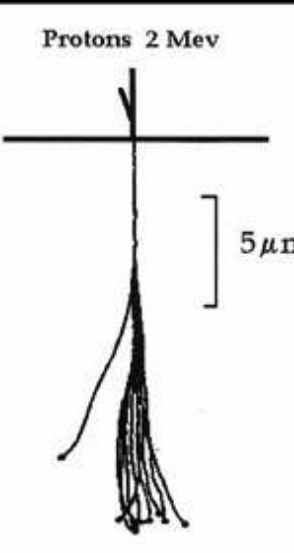

(b)

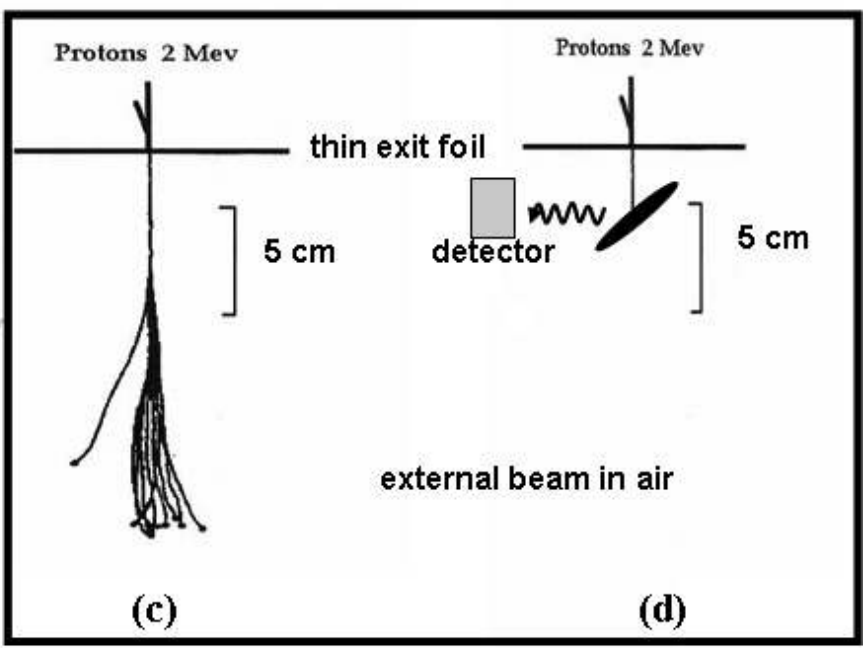

Figure 1: (a-b) Comparison of the interaction of electrons and protons with copper in vacuum. (c-d) Use of the trajectory of protons for non-vacuum analysis.

Figure $1:(a-b)$ Comparaison de l'interaction des électrons et des protons avec le cuivre dans le vide. (c-d) Utilisation des trajectoires des protons pour l'analyse en dehors de l'enceinte de l'accélérateur. 


$$
E_{\text {scatt }}=\left(\frac{M-m}{M+m}\right)^{2} E_{i}=K(M, m) E_{i}
$$

and to the depth in the material at which the scattering took place. When protons are used as incident particles, $\mathrm{K}$ (called the kinematic factor) is very close to 1 for all the components of $\mathrm{Au}-\mathrm{Ag}-\mathrm{Cu}$ alloys $(\mathrm{K}=0.94$ for $\mathrm{Cu}, 0.96$ for $\mathrm{Ag}$ and 0.98 for $\mathrm{Au}$ ), and the depth profile is very limited. The use of heavier projectiles like $\alpha$-particles (with $\mathrm{K}$ $=0.78,0.86,0.92$ for $\mathrm{Cu}, \mathrm{Ag}$ and $\mathrm{Au}$, respectively) is not recommended, due to their low range in materials (about 12 times less than for protons), and consequently their important energy loss in the exit foil of the accelerator, which prevents the use of an external beam, apart from using a very narrow beam crossing a thin $\mathrm{Si}_{3} \mathrm{~N}_{4}$ membrane of $0.1 \mu \mathrm{m}$ or so. Furthermore, the linear energy transfer of heavy incident ions in the irradiated sample would produce an undesired heating of the precious samples when the jewellery item is bombarded in the vacuum. As the cross-section for such elastic scattering is proportional to the $\mathrm{Z}^{2}$ of the target atoms, RBS is better suited for the study of low concentrations of high $\mathrm{Z}$ elements in light matrices, and is then mostly incompatible with the study of low concentrations of copper and silver in gold-rich jewellery items.

The probability for a Coulomb excitation of a target nucleus leading to the emission of a characteristic $\gamma$-ray is much lower than both the probability of backscattering leading to RBS and the probability of inner shell ionisation phenomena leading to PIXE. Consequently, PIGE (Particle Induced $\gamma$-ray Emission) is of particular interest for the study of light elements, where PIXE and RBS suffer from a lack of sensitivity and accuracy. For these light target elements, the energy of the characteristic X-rays is so low that they are absorbed into the material itself and RBS offers a lower cross section.

If the energy of the incident particle is maintained below $3 \mathrm{MeV}$, no delayed radioactivity may be induced as in CPAA (Charged Particle Activation Analysis), typically performed at incident energies greater than $10 \mathrm{MeV}$.

The interaction of a loosely bound compound projectile (like a deuteron) gives rise to the emission of energetic protons after the stripping of the incident ion. This is known as NRA. For instance, the breakdown of the incident deuteron may be written as: ${ }^{32} \mathrm{~S}\left(\mathrm{~d}, \mathrm{p}_{0}\right)^{33} \mathrm{~S}$. The stripping of the incident deuteron by a ${ }^{32} \mathrm{~S}$ nucleus leads to the capture of a neutron in ${ }^{32} \mathrm{~S}$ and leaves the ${ }^{33} \mathrm{~S}$ nucleus in its fundamental state, with an emitted proton with a maximum energy. Various other procedures could be employed to leave the residual nucleus of ${ }^{33} \mathrm{~S}$ in one of its $(\mathrm{i}=1,2,3)$ excited states. The corresponding energies of the $p_{i}$ protons are then lower than those for $\mathrm{p}_{0}$. The stored energy in the excited ${ }^{33} \mathrm{~S}^{*}$ nucleus will shortly give rise to a cascade of characteristic $\gamma$-rays. Several groups of protons of different energies, as well as $\gamma$-rays, may be used for analytical purposes.

As deuterons of energies in the $\mathrm{MeV}$ range cannot approach heavy nuclei like $\mathrm{Cu}, \mathrm{Ag}$ and $\mathrm{Au}$ due to the Coulomb barrier, this type of $(\mathrm{d}, \mathrm{p})$ reaction is particularly useful to complement PIXE and RBS. Sulphides are indeed expected to be sometimes present in solders of gold artefacts if ores were directly alloyed with a basic $\mathrm{Au}-\mathrm{Ag}-\mathrm{Cu}$ to obtain a low melting point alloy suitable for soldering. By using simultaneously (or sequentially) all these analytical techniques, one may achieve a very powerful characterisation of gold jewellery items.

We can then summarise our argument by this final recommendation regarding ion beam techniques: PIXE is the most appropriate method for the elemental analysis of the gold items, achieving the necessary accuracy for a complete quantitative determination of medium and heavy elements; PIGE would be used only if it is compulsory to analyse light elements. RBS, usually recommended to provide depth information on medium and heavy elements, is generally not sufficiently efficient for quantitatively separating information on $\mathrm{Cu}, \mathrm{Ag}$ and $\mathrm{Au}$ components, due to the high content of $\mathrm{Au}$, but would be interesting to use as a complement to the PIXE results on items which are non-homogeneous in their depth. NRA, inducing the transmutation of light elements, would complement PIGE in determining their depth profile. Below $3 \mathrm{MeV}$, no delayed radioactivity is induced.

Another popular, quantitative and non-destructive analytical technique whose performances are similar to PIXE is XRF. The methodology used to detect elements is exactly the same for PIXE and XRF. The main difference between the two lies in the ionisation process of the inner shells of atoms.

In XRF, the incident radiation is a photon whose energy is meant to be higher than the ionisation energy of the atom to be analysed, and also higher than the energy of the characteristic X-ray line to be detected. The depth from which the characteristic $\mathrm{L}$ lines of $\mathrm{Au}$, and $\mathrm{K}$ lines of $\mathrm{Ag}$ and $\mathrm{Cu}$ are emitted is then deeper than for PIXE, due to the high energy of the $\mathrm{Ag}$ lines. Incident $\mathrm{X}$-rays of about $35 \mathrm{keV}$ are then necessary, which would involve an important absorption of emitted signals from $\mathrm{Cu}$ and $\mathrm{Au}$. Working with lower incident photon energy would require to analyse $\mathrm{Ag}$ with their characteristic L lines which would concern a too low bulk information. Nevertheless, XRF is a powerful technique, much cheaper than PIXE, and is likely to be more extensively used than PIXE due to its easiness of transportation to museums and excavation sites. 


\section{TARGETING PIXE FOR GOLD JEWELLERY ITEMS}

With the exception of trace elements, PIXE is a very appropriate technique for the quantitative analysis of major and minor elements in gold jewellery artefacts. To increase the sensitivity for the study of objects with low concentrations of $\mathrm{Cu}$ and $\mathrm{Ag}$, it is often compulsory to selectively decrease the intensity of the AuL X-ray lines by inserting a thin foil (20 to 30 microns) of $\mathrm{Zn}$ (or $\mathrm{Cu}$ ) between the target and the detector. The huge increase of the absorption at $9.66 \mathrm{keV}$ for $\mathrm{Zn}$ and at $8.98 \mathrm{keV}$ for $\mathrm{Cu}$ justifies their use in the filtering of gold L lines. A 20 microns-thick foil of $\mathrm{Zn}$ reduces the intensity of the L $\alpha$ line by a factor of 45 and that of the $L \beta$ line of $A u$ by a factor of 11.5 , but only by factors of 2.4 and 1.5 the $\mathrm{K} \alpha$ lines of $\mathrm{Cu}$ and $\mathrm{Ag}$, respectively. One can see (Table 1) that, for an interference-free detection, the $\mathrm{K} \alpha$ lines of $\mathrm{Cu}$ and $\mathrm{Ag}$, and the $\mathrm{L} \beta$ line of $\mathrm{Au}$ are the most appropriate. The calculation of the concentration of $\mathrm{Cu}$ would nevertheless include the computation of the escape peak of the L $\alpha$ line of Au in the region of the $\mathrm{K} \alpha$ line of $\mathrm{Cu}$. The $\mathrm{Zn}$ concentration would be impossible due to the complete interference of both $\mathrm{Zn} \mathrm{K}$-lines with the $\mathrm{Ll}$ and $\mathrm{L} \alpha$ lines of Au. The concentration of $\mathrm{Cd}$ (often useful for the detection of fakes or modern repairs) is not easy, due to the interference with the sum peak (twice 11.5 $\mathrm{keV}$ ) of the very intense $\mathrm{L} \beta$ line of Au. The complete computation of the elemental concentrations is carried out using a home-made programme taking into account all the necessary physical processes, including the secondary fluorescence induced mainly by the Au L lines in $\mathrm{Cu}$ (Van Oystaeyen and Demortier, 1983; Demortier and Morciaux, 1994), or by using other commercial computer programmes.
Most of the PIXE users working in the field of archaeometry select protons as incident particles in a non-vacuum geometry and tune their accelerator above $3 \mathrm{MeV}$ (Calvo del Castillo et al., 2008; Bugoi et al., 2008; Migliori et al., 2008; Quarta et al., 2008; Mathis et al., 2008). Their main arguments for this are:

- the higher the incident energy, the lower is the energy deposited in the exit foil;

- the higher the incident energy, the higher is the crosssection for X-ray emission for all the elements of the target (see Fig. 2).

Let us comment on this general attitude. In order to probe the maximum distance in the irradiated material, the maximum incident energy seems to be the most appropriate, and the sample is to be irradiated with its surface normal to the beam direction, as illustrated in Figure 1d. In this geometry, the X-ray detector (made with a silicon wafer) is situated at an angle of about $135^{\circ}$ relative to the incident beam and the outgoing X-rays path is longer by a factor of 1.42 relative to the incident particle path.

In Table 2 we provide the proportion of outgoing characteristic X-rays of $\mathrm{Cu}, \mathrm{Ag}$ and $\mathrm{Au}$ for a series of typical gold alloys. One can observe (first line in the table) that only $22.5 \%$ of the entire intensity of the Au L $\alpha$ produced by 3 $\mathrm{MeV}$ protons may escape from a homogeneous alloy $(50 \%$ $\mathrm{Au}, 25 \% \mathrm{Ag}$ and $25 \% \mathrm{Cu}$ sample), but this proportion increases up to $67.8 \%$ when the incident energy is lowered down to $1 \mathrm{MeV}$. The detected $\mathrm{K} \alpha$ line of $\mathrm{Cu}$ follows the same trend, but the $\mathrm{Ag} \mathrm{K \alpha}$ is much less affected by this absorption effect. At proton incident energies above $2 \mathrm{MeV}$, most of the emitted X-rays of $\mathrm{Cu}$ and $\mathrm{Au}$ are absorbed in the target itself. For low concentrations of copper in gold rich

\begin{tabular}{|c|c|c|c|c|c|}
\hline Element & X-ray & Energy $(\mathrm{keV})$ & Selection & Remarks & Interference \\
\hline \multirow{2}{*}{$\mathrm{Fe}$} & $\mathrm{K} \alpha$ & 6.4 & yes & traces of ores & escape of $\mathrm{CuK} \alpha$ \\
\hline & $\mathrm{K} \beta$ & 7.06 & & & \\
\hline \multirow{2}{*}{$\mathrm{Cu}$} & $\mathrm{K} \alpha$ & 8.04 & yes & main or minor & escape of AuL $\alpha$ \\
\hline & $\mathrm{K} \beta$ & 8.9 & & & \\
\hline \multirow{2}{*}{$\mathrm{Zn}$} & $\mathrm{K} \alpha$ & 8.64 & & traces? & with AuLl \\
\hline & $\mathrm{K} \beta$ & 9.6 & & & with $A u L \alpha$ \\
\hline \multirow{2}{*}{$\mathrm{Ag}$} & $\mathrm{K} \alpha$ & 22,1 & yes & & \\
\hline & $\mathrm{K} \beta$ & 24.9 & & & \\
\hline \multirow{2}{*}{$\mathrm{Cd}$} & $\mathrm{K \alpha}$ & 23.1 & yes & & sum twice $A u L \beta$ \\
\hline & $\mathrm{K} \beta$ & 26.1 & & & low intensity \\
\hline \multirow{3}{*}{$\mathrm{Au}$} & $\mathrm{L} \alpha$ & 9.6 & & large absorption in filter & with $\mathrm{ZnK} \beta$ \\
\hline & $L \beta$ & 11.5 & yes & & \\
\hline & $\mathrm{Ll}$ & 8.4 & & & with $\mathrm{ZnK} \alpha$ \\
\hline
\end{tabular}

Table 1: Characteristic X-ray lines used for the analysis of gold jewellery items.

Tableau 1 : Raies X caractéristiques utilisées pour l'analyse des objets d'orfeurerie. 


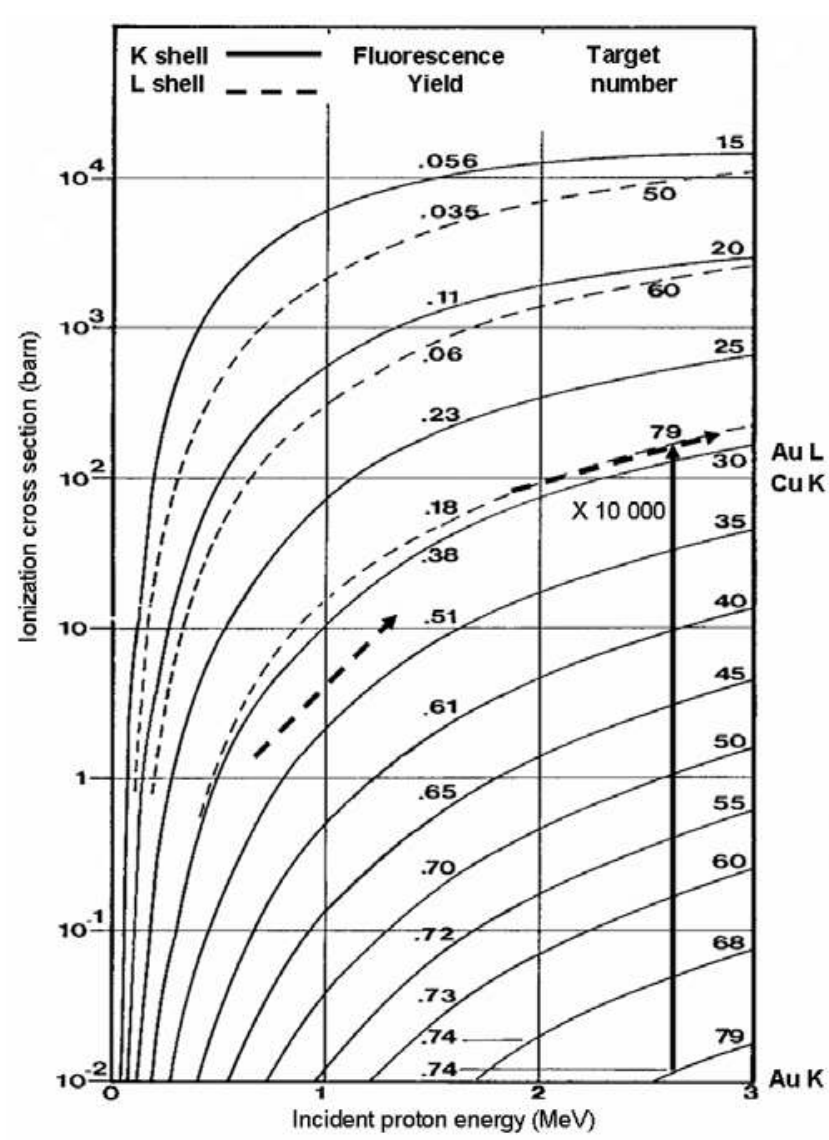

Figure 2: Variation of the ionization cross-section for $\mathrm{K}$ and $\mathrm{L}$ shells with protons.

Figure 2 : Variation de la section efficace d'ionisation des couches $K$ et $L$ avec des protons.

artefacts, this absorption effect reaches $85 \%$ at $3 \mathrm{MeV}$ (last line in Table 2). The quantitative determination is then very highly affected by irregularities in the artefact's surface or by the incorrect reproducibility of the sample surface orientation relative to the direction of the incident beam. We also observe that the absorption of the L $\alpha$ line of gold is much higher than the absorption of the $\mathrm{L} \beta$ line, justifying the reason for selecting this $L \beta$ line for the calculation of gold concentration. Due to its high energy, the K $\alpha$ line of silver is less sensitive to any absorption effect. A careful choice of the position and of the size of the zinc filter is compulsory in order to avoid additional detection of zinc $\mathrm{K} \mathrm{X}$-ray lines in the detector. This fluorescence effect has been extensively discussed in previous works [Demortier et al., 1993; Demortier and Morciaux, 1994). When all the parameters of the geometry of detection are known, PIXE is an absolute method of analysis, but the technology is even more straightforward when the measurement is made by com- parison with a homogeneous reference material containing all the elements of interest. Incident beam intensity, detector efficiency, detector solid angle, duration of the irradiation, computation of absorption of X-rays in the material between the sample and the detector would not be measured (Demortier et al., 1990).

\section{Differential PIXE FOR DEPTH PROFILING OF GILDED ARTEFACTS}

A layered structure cannot be detected by PIXE using incident protons at a single energy. As explained above, RBS is not able to easily separate scattered particles on $\mathrm{Cu}, \mathrm{Ag}$ and Au. Differential PIXE is able to achieve this goal even for thicknesses up to $10 \mu \mathrm{m}$ (Demortier and Ruvalcaba, 2005). The $\mathrm{CuK} \alpha / \mathrm{AuL} \beta$ intensity ratio is very different for a homogeneous material or a layered structure, and this ratio varies in opposite ways if the material is irradiated at various incident proton energies. The explanation is given in Figure 4. In full lines we give the variation of the $\mathrm{CuK} \alpha / \mathrm{AuL} \beta$ ratio for a layered structure and in doted lines the behaviour for homogeneous alloys. Thus, if a sample made of pure $\mathrm{Cu}$ covered with a $4 \mu \mathrm{m}$ thick layer of gold is irradiated with 1.8 $\mathrm{MeV}$ protons, the ratio is 0.86 (point $\mathrm{A}$ ), but increases up to 2.05 if the incident proton energy is $2.6 \mathrm{MeV}$ (point $\mathrm{B}$ ), and decreases down to 0.17 (point $\mathrm{D}$ ) if the proton energy is $1.2 \mathrm{MeV}$. At $1.8 \mathrm{MeV}$, this ratio of 0.86 would correspond to a homogeneous alloy containing $92 \% \mathrm{Au}$ and $8 \% \mathrm{Cu}$, but this ratio would decrease down to 0.71 at $2.6 \mathrm{MeV}$ and increase up to 0.96 at $1.2 \mathrm{MeV}$. The variations are then in the opposite directions. Furthermore, the variation is very sharp for a layered structure, and smooth for a homogeneous alloy. The slope of the variation of the $\mathrm{CuK \alpha} / \mathrm{AuL} \beta$ ratio is increasing when the incident proton energy is decreased. The choice of an incident energy in the region of $2 \mathrm{MeV}$ is then optimal. In addition to a lower absorption of the X-ray lines at lower proton energy, we add now a better capability to detect surface enhancement or depletion.

In order to apply this differential PIXE technique to materials with a depth profile down to several microns, measurements of the $\mathrm{CuK} \alpha / \mathrm{AuL} \beta$ ratio are to be made at $\mathrm{n}$ different proton energies to obtain the $\mathrm{Cu} / \mathrm{Au}$ intensity ratio in $\mathrm{n}-1$ layers and in the bulk. For instance, if we assume that the anthropo-zoomorphic pendant (Quimbaya Peru - 1000 to 1600 AD) shown in Figure 5 is homogeneous, conventional PIXE data obtained with protons of energies ranging from 0.6 to $2.6 \mathrm{MeV}$ would give contradictory results (Table 3) for the analysis at the same impact on the sample but at different incident beam energies. Thus, the $\mathrm{Cu}$ content 


\begin{tabular}{|c|c|c|c|c|c|c|c|}
\hline & $\%$ & $\mathrm{X}-$ ray & $3.0 \mathrm{MeV}$ & $2.5 \mathrm{MeV}$ & $2.0 \mathrm{MeV}$ & $1.5 \mathrm{MeV}$ & $1.0 \mathrm{MeV}$ \\
\hline $\mathrm{Au}$ & 50 & $\mathrm{~L} \alpha$ & 22.5 & 28.9 & 39.9 & 50.6 & 67.8 \\
& & $\mathrm{~L} \beta$ & 26.3 & 39.4 & 49.3 & 61.9 & 76.6 \\
$\mathrm{Ag}$ & 25 & $\mathrm{~K} \alpha$ & 60.8 & 68.2 & 75.8 & 83.9 & 93.0 \\
$\mathrm{Cu}$ & 25 & $\mathrm{~K} \alpha$ & 21.3 & 27.7 & 36.9 & 49.4 & 65.2 \\
\hline $\mathrm{Au}$ & 50 & $\mathrm{~L} \alpha$ & 21.2 & 27.4 & 36.3 & 49.1 & 66.7 \\
& & $\mathrm{~L} \beta$ & 30.0 & 37.6 & 47.6 & 60.5 & 75.8 \\
$\mathrm{Ag}$ & 5 & $\mathrm{~K} \alpha$ & 60.7 & 68.5 & 76.8 & 82.0 & 95.0 \\
$\mathrm{Cu}$ & 45 & $\mathrm{~K} \alpha$ & 26.7 & 34.2 & 44.4 & 56.8 & 71.8 \\
\hline $\mathrm{Au}$ & 75 & $\mathrm{~L} \alpha$ & 22.2 & 28.4 & 37.1 & 41.8 & 68.8 \\
& & $\mathrm{~L} \beta$ & 31.1 & 38.6 & 48.1 & 60.9 & 75.9 \\
$\mathrm{Ag}$ & 15 & $\mathrm{~K} \alpha$ & 51.5 & 59.5 & 68.5 & 77.9 & 90.0 \\
$\mathrm{Cu}$ & 10 & $\mathrm{~K} \alpha$ & 17.5 & 23.0 & 31.1 & 42.8 & 58.3 \\
\hline $\mathrm{Au}$ & 80 & $\mathrm{~L} \alpha$ & 22.3 & 28.4 & 37.2 & 49.6 & 66.7 \\
& & $\mathrm{~L} \beta$ & 31.2 & 38.6 & 48.4 & 60.8 & 75.7 \\
$\mathrm{Ag}$ & 15 & $\mathrm{~K} \alpha$ & 49.7 & 57.7 & 66.5 & 76.4 & 90.0 \\
$\mathrm{Cu}$ & 5 & $\mathrm{~K} \alpha$ & 16.5 & 21.8 & 29.4 & 40.8 & 56.2 \\
\hline $\mathrm{Au}$ & 96 & $\mathrm{~L} \alpha$ & 21.6 & 27.6 & 35.5 & 47.4 & 63.9 \\
& & $\mathrm{~L} \beta$ & 30.2 & 37.5 & 46.5 & 58.7 & 73.4 \\
$\mathrm{Ag}$ & 3.5 & $\mathrm{~K} \alpha$ & 44.2 & 52.3 & 62.0 & 69.6 & 100.0 \\
$\mathrm{Cu}$ & 1.5 & $\mathrm{~K} \alpha$ & 15.1 & 19.8 & 26.9 & 27.9 & 53.8 \\
\hline
\end{tabular}

Table 2: Percentage of outgoing X-rays of $\mathrm{Cu}, \mathrm{Au}$ and $\mathrm{Ag}$ used in the PIXE analysis of jewellery items with protons of various energies. Tableau 2 : Pourcentage des rayons Xémergeant du Cu, de l'Au et de l'Ag utilisés pour l'analyse des objets d'orfevrerie par PIXE avec des protons d'énergies variées.

\begin{tabular}{|c|c|c|c|}
\hline $\begin{array}{c}\text { Depth below } \\
\text { surface }(\mu \mathrm{m})\end{array}$ & $\begin{array}{c}\mathrm{Cu} \\
\%\end{array}$ & $\begin{array}{c}\mathrm{Au} \\
\%\end{array}$ & $\begin{array}{c}\mathrm{Ag} \\
\%\end{array}$ \\
\hline 0.28 & 0 & 94 & 6 \\
\hline 0.28 & 4 & 90 & 6 \\
\hline 0.28 & 8 & 86 & 6 \\
\hline 0.28 & 12 & 82 & 6 \\
\hline 0.28 & 16 & 74 & 6 \\
\hline 0.28 & 24 & 70 & 6 \\
\hline bulk & 28 & 68 & 6 \\
\hline
\end{tabular}

Table 3: Depth profile of elements in the Quimbaya pendant obtained by differential PIXE.

Tableau 3 : Profils en profondeur dans le pendentif Quimbaya par PIXE différentiel.

appears to be $8.6 \%$ at $0.6 \mathrm{MeV}$ incident proton energy (in that case, most of the signal comes from the first 2 microns below the surface), but increases up to $18.7 \%$ at $2.6 \mathrm{MeV}$ proton energy (most of the $\mathrm{X}$-rays are coming in this case from a thicker layer, of about ten microns). The sample is then certainly not homogeneous in depth, but is highly enriched in gold on the surface. Repeating the measurement at 7 different proton energies, we have computed by an iteration method (similar to the one used for RBS spectra) that the depth distribution of $\mathrm{Cu}$ varied from 0 to $28 \%$ from the surface to a depth of 1.7 micron below the surface. The identification of nearly no copper on the surface was verified using PIXE with incident low energy $\alpha$ particles. Differential PIXE has also been applied to other materials (Smit et al., 2008).

\section{DETERMINATION OF TRACES OF SULPHUR AND ZINC IN ANCIENT GOLD ARTEFACTS}

PIXE has been successfully applied for the purposes of topographical elemental analysis of $\mathrm{Cu}, \mathrm{Ag}$, and $\mathrm{Au}$ in jewellery items. The composition of the material in narrow regions of minute solders on antique gold artefacts may provide valuable information regarding the workmanship 
Figure 3: Mass absorption coefficient of X-rays in $\mathrm{Cu}, \mathrm{Zn}, \mathrm{Ag}$ and $\mathrm{Au}$, to be used in selective filters and for XRF induced by PIXE. massique des rayons $X$ dans le $C u$, le Zn, l'Ag et l'Au à utiliser pour les filtres sélectifs et pour la FX induite par PIXE.
Figure 3 : Coefficient d'absorption

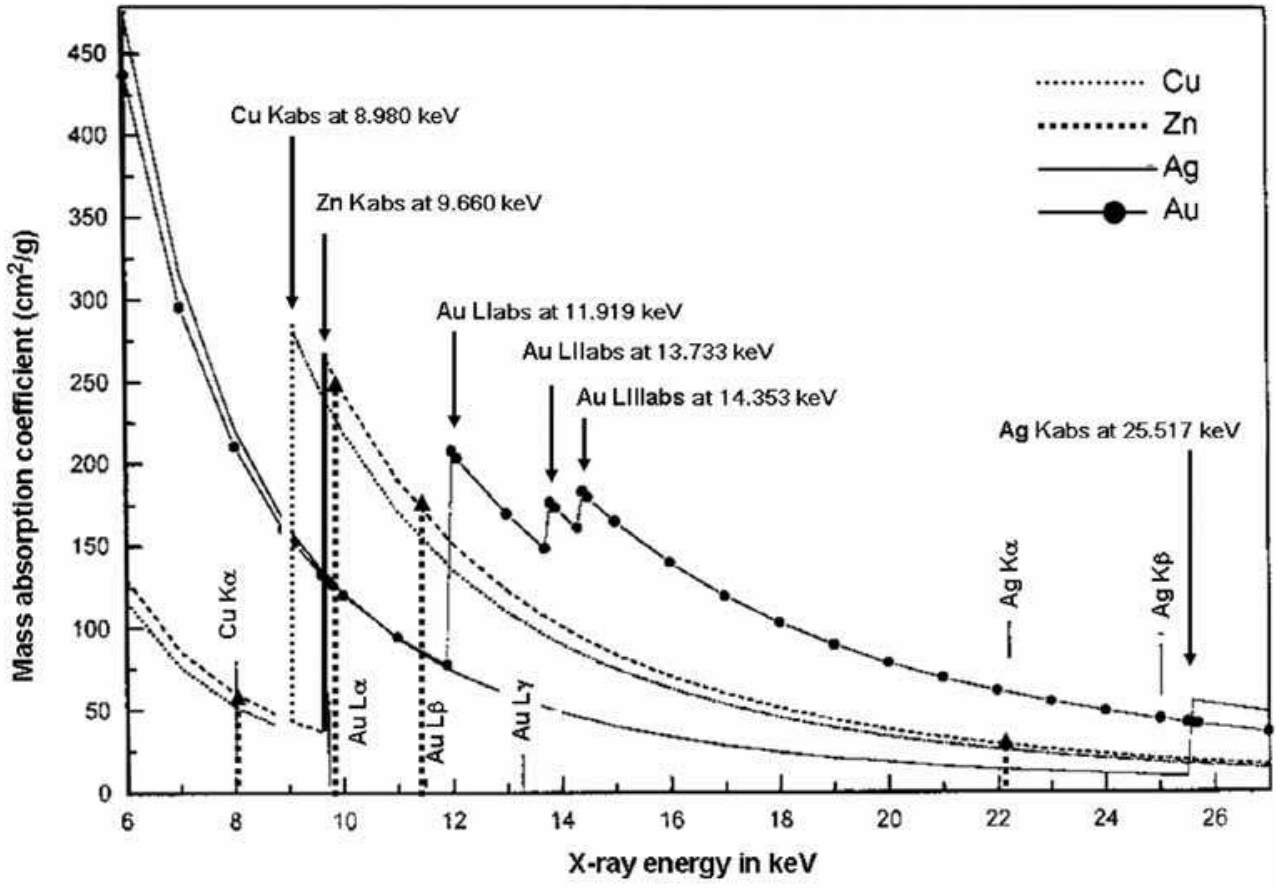

of goldsmiths from the Ancient World. We have shown above that $\mathrm{Zn}$ is difficult to analyse by PIXE due to the high interference of its K-lines with the L-lines of gold, and that signals of $\mathrm{Cd}$ are very often neglected due to the high probability of interference with pile-up signals: the K $\alpha$ energy of $\mathrm{Cd}$ is exactly at the position of twice the $\mathrm{L} \beta$ line of gold. In several previous papers, we have discussed the hypothesis that, in ancient times, cadmium sulphide (a yellow mineral with a colour close to that of gold) may have been 'alloyed' with gold to obtain a material suitable for brazing. To test this hypothesis, an experimental procedure for the analysis of traces of sulphur in gold artefacts was developed. It is indeed expected that during the ancient alloying procedure, traces of sulphur from the cadmium sulphide were introduced in the brazing alloy.

The detection of energetic protons induced by a deuteron bombardment of the specimen under investigation was achieved. The best experimental conditions for sulphur determination are obtained by $(\mathrm{d}, \mathrm{p})$ reactions at $\mathrm{E}_{\mathrm{d}}$ $=1.9 \mathrm{MeV}$ and a detection angle of protons around $165^{\circ}$ (Demortier and Gilson, 1987). S signals are well separated

Figure 4: Variation of the CuK $\alpha / A u L \beta$ intensity ratio for layered and homogeneous $\mathrm{Cu}-\mathrm{Au}$ alloys under proton bombardment.

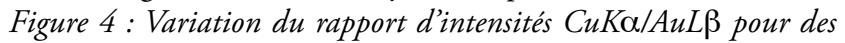
alliages Cu-Au stratifiés et homogènes sous bombardement de protons.

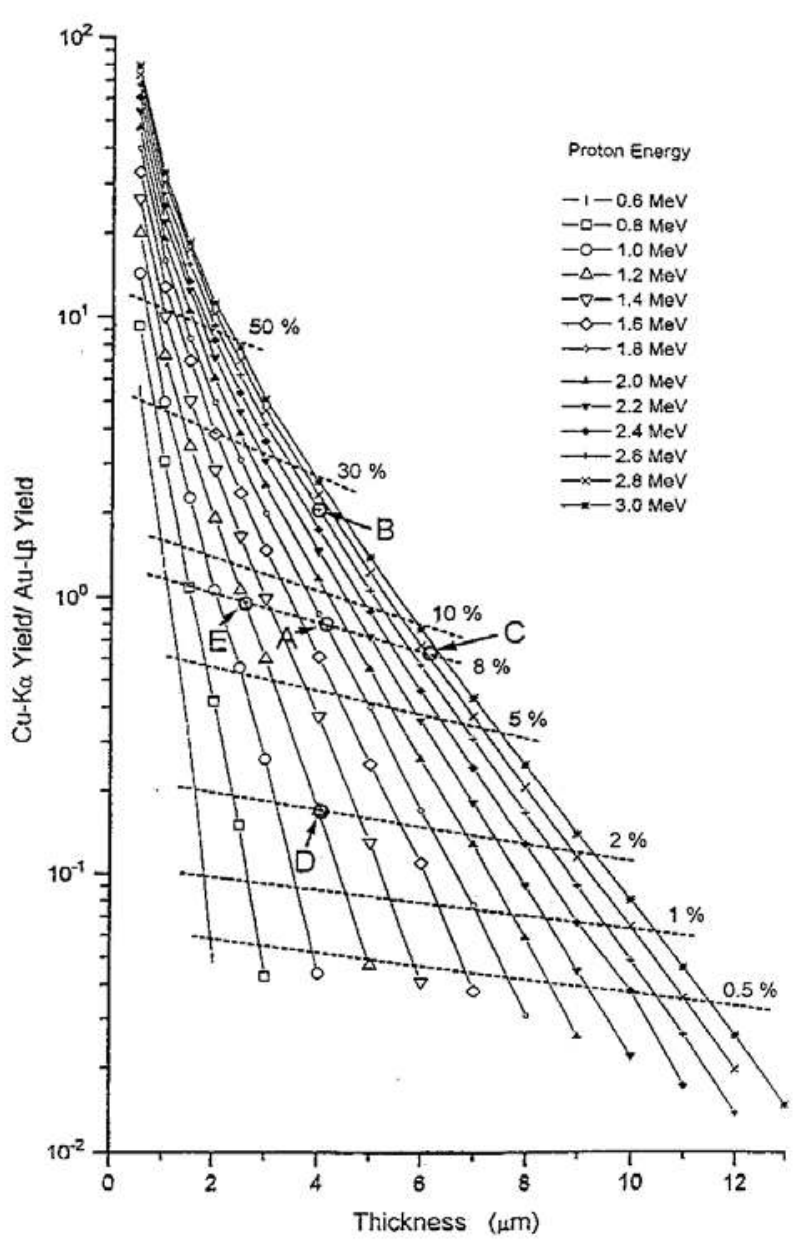

ArCheoSCIEnCes, revue d'archéométrie, 33, 2009, p. 29-38 


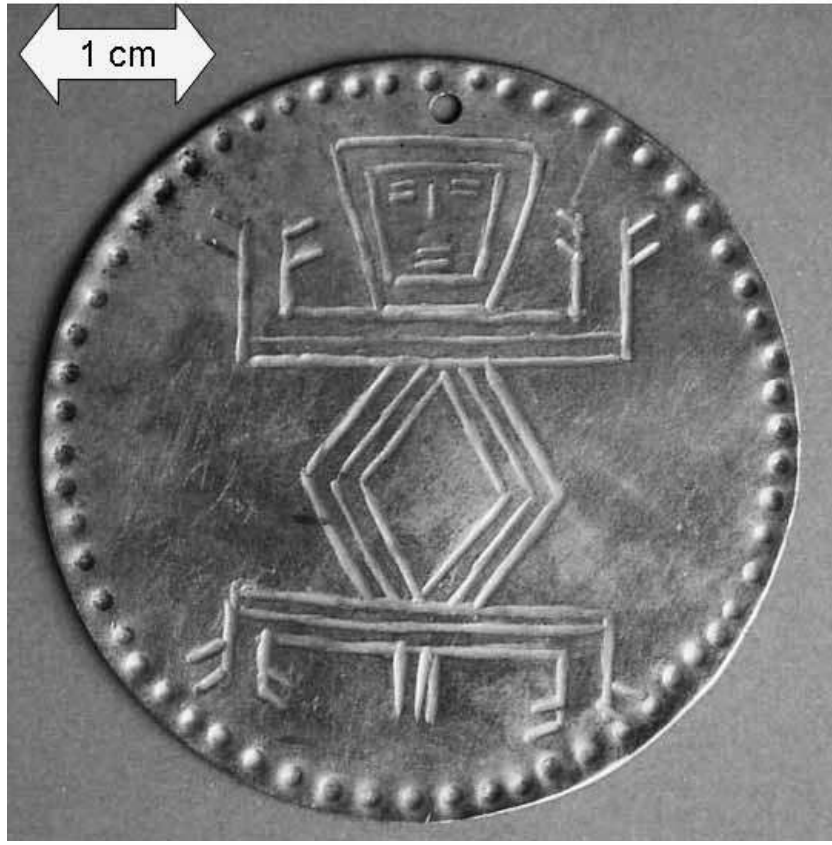

Figure 5: (See colour plate) The Quimbaya pendant (Colombia, 1000-1600 AD).

Figure 5 : (Voir planche couleur) Le pendentif Quimbaya (Colombie 1000-1600 A.D.) from those of $\mathrm{Si}, \mathrm{Mg}, \mathrm{Cl}, \mathrm{Ca}\left(\right.$ for $\mathrm{p}_{0}$ ) and $\mathrm{Al}, \mathrm{P}, \mathrm{Cl}, \mathrm{K}, \mathrm{Mg}$ $\left(\right.$ for $\left.\mathrm{p}_{1}\right)$. The complete discussion is provided elsewhere.

Sulphur and silicon (always introduced in metals when heating ores in ancient metallurgy) are of crucial importance for the understanding of ancient technologies. Sulphur (in blende and greenockite) and silicon (in a number of minerals) may be expected to be present in narrow parts of solders made during the brazing of ancient gold artefacts. The detected concentrations of $\mathrm{S}$ and $\mathrm{Si}$ were in the range of 50 to $120 \mathrm{ppm}$. The concentration of Cd was simultaneously determined by the detection of characteristic X-rays induced by the deuteron beam. This presence of residual sulphur (only at trace level) indicates that at least $95 \%$ of $S$ was lost during the alloying procedure. The presence of traces of Si and often also traces of $\mathrm{Al}$ can be also attributed to dust inclusions in narrow regions of solders (Demortier and Gilson, 1987).

Cadmium ores (and mainly CdS) always contain zinc as impurities. Modern brazing alloys containing $\mathrm{Cd}$ are $\mathrm{Zn}$ free or have a $\mathrm{Zn}$ concentration of about $20 \%$ of the $\mathrm{Cd}$ concentration. The measurement of the $\mathrm{Zn} / \mathrm{Cd}$ ratio would therefore be of great interest for differentiating brazing alloys containing $\mathrm{Cd}$ of ancient or modern origin. As the measurement of $\mathrm{Zn}$ in gold rich alloys is impossible by PIXE due to

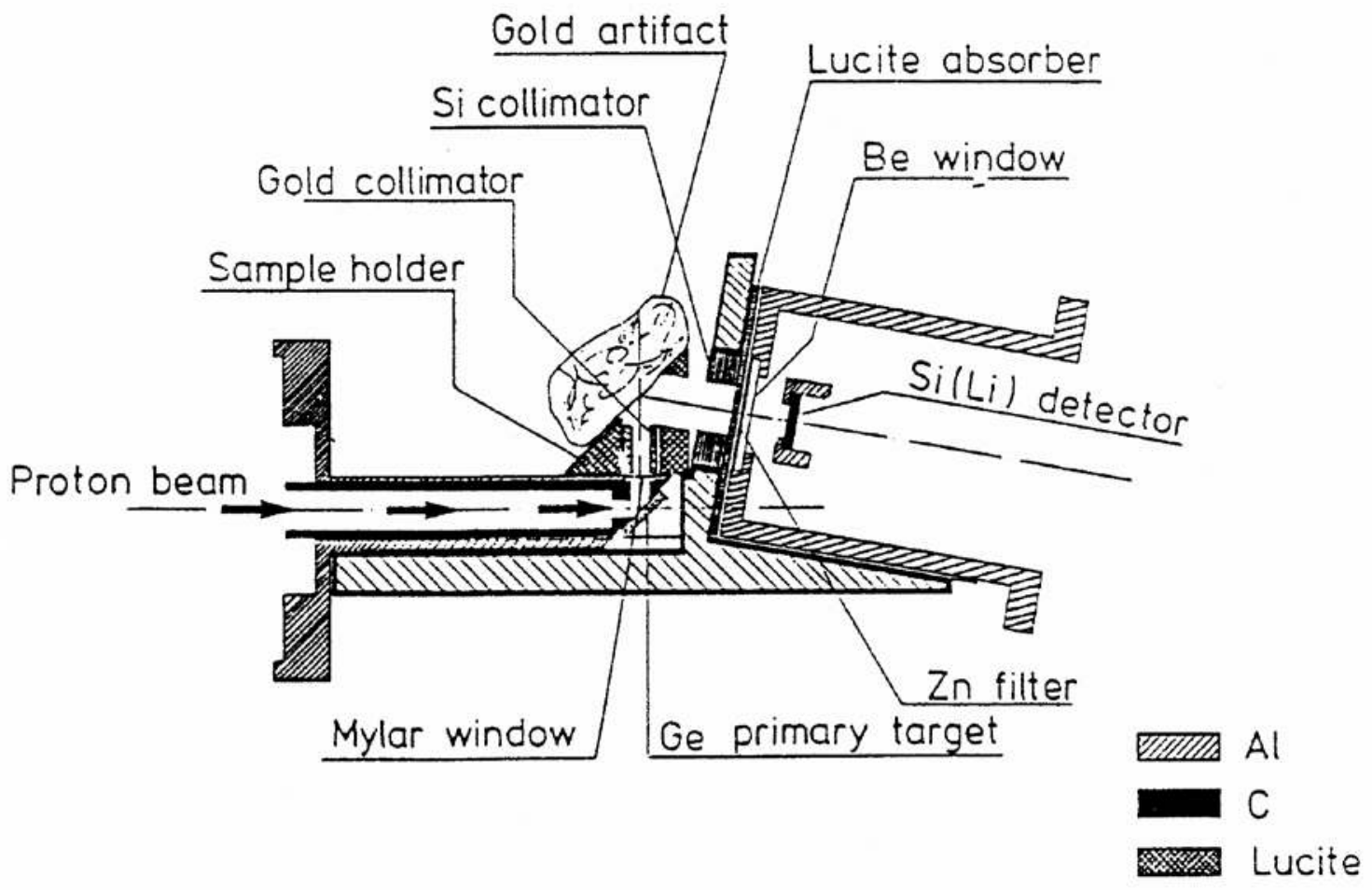

Figure 6: The experimental setup for the measurement of $\mathrm{Zn}$ in gold-rich samples using XRF induced by PIXE (Ge primary target). Figure 6: Le montage expérimental pour la mesure du Zn dans les alliages riches en or par FX induite par PIXE (cible primaire en Ge). 
the superposition of the $\mathrm{K}$ lines of $\mathrm{Zn}$ with the $\mathrm{L}$ lines of $\mathrm{Au}$, we have developed a technique involving XRF induced by PIXE in order to selectively excite the $\mathrm{K}$ lines of $\mathrm{Zn}$ without exciting the $\mathrm{L}$ lines of $\mathrm{Au}$ (Demortier, 1987). The irradiation of a pure Ge target with protons (and not with electrons, in order to avoid any contribution of Bremtrahlung) produces $\mathrm{X}$-rays of 9.89 and $10.98 \mathrm{keV}$, which are sufficient to extract $\mathrm{K}$-shell electrons from $\mathrm{Zn}$ but not the L-shell of gold (see Figure 3). The same arrangement, using As as primary target, has been used by the team of M. Guerra to detect traces of Pt in gold (Guerra and Calligaro, 2003; 2004). The experimental assembly is shown in Figure 6. Our personal view on the possible use of $\mathrm{Cd}-\mathrm{Cu}-\mathrm{Ag}-\mathrm{Au}$ alloys in antiquity has been extensively discussed, but our conclusions are far from being generally accepted (Demortier, 1987; 1989; 1992; Meeks and Craddock, 1991).

\section{Conclusions}

Of the different ion beam analysis techniques (PIXE, RBS, PIGE and NRA), PIXE is the most appropriate technique using low energy accelerators for the analysis of gold jewellery artefacts. A careful choice of the characteristic X-ray lines may help one avoid interferences in the identification of signals of selected elements, such as Zn or Pt. XRF induced by PIXE offers additional possibilities of interferencefree analyses. Irradiation at various incident proton energies offers the possibility to detect and to quantitatively and nondestructively profile major elements up to 10 microns below the surface. The choice of an incident proton energy around $2 \mathrm{MeV}$ offers the advantage of a sharp variation of the X-ray emission cross, useful in order to easily distinguish a layered structure from one with a homogeneous distribution of the elements.

\section{References}

Bugoi, R., Cojocaru, V., Constantinescu, B., Calligaro, T., Pichon, L., Röhrs, St. and Salomon, J., 2008. Compositional studies on Transylvanian gold nuggets: advantages and limitations of PIXE-PIGE analysis. Nuclear Instruments and Methods B 266: 2316-2319.

Calvo del Castillo, H., Ruvalcaba, J.l., Calderon, T., Salinas Nolasco, M.F., Mejia, L.M. and Perdigon, K., 2008. Characterisation of an enamelled metallic object found in Guerrero Negro (Baja California) by PIXE and RBS techniques. Nuclear Instruments and Methods B 266: 2311-2315.
DeconnincK, G., 1972. Quantitative analysis by (p,g) and (p,X) reactions at low energies. Journal of Radioanalytical Chemistry 12: $157-169$.

Demortier, G., 1987. Trace analysis of medium $Z$ elements in narrow regions of a heavy matrix by XRF induced by PIXE, in J.D. Brown, R.H. Packwood (eds.), $11^{\text {th }}$ International Congress on $X$-ray optics and microanalysis. London: University of Western Ontario, 147.

Demortier, G., 1987. La chrysocolle des orfèvres est-elle jaune? Archaeometry 29(2): 275-288.

Demortier, G., 1989. Ancient gold solders: what was chrysocolla?, in R.O. Allen (ed.), Archaeological Chemistry IV, Advances in Chemistry Series 220. Washington, DC: American Chemical Society: 249-263.

Demortier, G., 1992. Comments on Meeks and Craddock's position on cadmium in solders. Archaeometry 34(2): 305-319.

Demortier, G. and Gilson, A., 1987. Determination of traces of light elements in gold artefacts using nuclear reactions. Nuclear Instruments and Methods B 18: 286-290.

Demortier, G. and Morciaux, Y., 1994. PIXE gadgets. Nuclear Instruments and Methods B 85: 112-117.

Demortier, G. and Ruvalcaba, J.L., 2005. Quantitative ion beam analysis of complex gold based artefacts. Nuclear Instruments and Methods B 239: 1-15.

Demortier, G., Mathot, S. and Van Oystaeyen, B., 1990. Complementarity of RBS,PIGE and PIXE for the determination of surface layers of thicknesses up to 25 microns. Nuclear Instruments and Methods B 49: 46-51.

Demortier, G., Mathot, S. and Steukers, C., 1993. Secondary effects in PIXE analysis of binary alloys and thick surface layers. Nuclear Instruments and Methods B 75: 347-354.

Guerra, M.F. and Calligaro, T., 2003. Gold cultural heritage objects: a review of studies of provenance and manufacturing technology. Measurement Science and Technology 14: 15271537.

Guerra, M.F. and Calligaro, T., 2004. Gold traces to trace gold. Journal of Archaeological Science 31( 9): 1199-1208.

Mathis, F., Vtielynck, O., Laclavetine, K., Chêne, G. and Strivay, D., 2008. Study of the provenance of Belgian Merovingian garnets by PIXE at IPNAS cyclotron. Nuclear Instruments and Methods B 266: 2348-2352.

Meeks, N.D. and Craddock, P.T., 1991. The detection of cadmium in gold/silver alloys and its alleged occurrence in ancient gold solders. Archaeometry 33(1): 95-107.

Migliori, M., Grassi, N. and Mando, P., 2008. Scanning PIXE analysis of gold lace embroideries in a relic of St. Francis. Nuclear Instruments and Methods B 266: 2339-2342.

Quarta, G., Butalag, K., Calcagnile, L., D’Elia, M., Arthur, P., Tinelli, M. and Caramia, A., 2008. IBA analyses and lead contamination measurements of AMS-14C dated bones from

ArCheoSCIEnCes, revue d'archéométrie, 33, 2009, p. 29-38 
two medieval sites in Italy. Nuclear Instruments and Methods B 266: 2343-2347.

Ruvalcaba, J.L. and Demortier, G., 1996. Elemental concentration profile in ancient artefacts by ion beam scattering. Nuclear Instruments and Methods B 113: 275-278.

Smit, Z., Istenic, J. and KNIFIC, T., 2008. Plating of archaeological objects: study by differential PIXE. Nuclear Instruments and Methods B 266: 2328-2333.
Van Oystaeyen, B. and Demortier, G., 1983. Matrix effects in PIXE evaluation of the major components in thick homogeneous samples. Nuclear Instruments and Methods 215: 299-313. 